\title{
Preoperative incidence and risk factors of deep vein thrombosis in patients with an isolated patellar fracture
}

\author{
Weijie Yang ${ }^{1 \dagger}$, Haicheng Wang ${ }^{1 \dagger}$, Qun Wei ${ }^{2}$, Kai Ding ${ }^{1}$, Yuxuan Jia ${ }^{3}$, Chao Li ${ }^{1}$, Yanbin Zhu ${ }^{1 *}$ and Wei Chen ${ }^{1 *}$
}

\begin{abstract}
Purpose: This study aimed to investigate the incidence, location, and related factors of preoperative deep venous thrombosis (DVT) in patients with isolated patellar fractures.

Methods: Patients with an isolated patellar fracture, admitted between January 2013 and December 2019 at our institution, were retrospectively analyzed. Upon admission, patients underwent routine Doppler ultrasound scanning (DUS) of the bilateral lower extremities to detect DVT; those with DVT were assigned to the case group and those without DVT to the control group. Patients in both groups did not perform preoperative off-bed weight-bearing exercises. Data on demographics, comorbidities, and laboratory test results upon admission were extracted. Variables were evaluated between the two groups using univariate analyses, and independent risk factors associated with DVT were identified by logistic regression analysis.
\end{abstract}

Results: During the study period, 827 patients were included, of whom 5.8\% (48/827) were found to have preoperative DVT. In DVT patients, 85.4\%(41/48) were injured, 8.3\%(4/48) were not injured, and 6.3\%(3/48) were lower limbs. Multivariate analysis showed that male (male vs. female, odds ratio, $O R=2.25$ ), delayed from injury to DUS (in each day, $\mathrm{OR}=1.29)$, and elevated plasma D-dimer level $(>0.5 \mu \mathrm{g} / \mathrm{mL}, \mathrm{OR}=2.47)$ were independent risk factors associated with DVT.

Conclusions: Despite the low prevalence of DVT after an isolated patellar fracture, this study underscores the importance of identifying those with a high risk of DVT, especially those with multiple identifiable factors, and encourage the early targeted use of anti-thromboembolic agents to reduce DVT occurrence.

Keywords: Patellar fracture, DVT, Incidence, Risk factors

\section{Introduction}

DVT of the lower extremities is one of the common complications in hospitalized patients, and it often leads to the occurrence of pulmonary embolism, especially in patients with traumatic fractures $[1,2]$.

*Correspondence: zhuyanbin111@126.com;drchenwei1@163.com ${ }^{\dagger}$ Weijie Yang and Haicheng Wang contributed equallyto this work. 1 Trauma Emergency Center, Key Laboratory of Biomechanics of Hebei Province, the Third Hospital of Hebei Medical University, No. 139 Ziqiang Road, Qiaoxi District, Shijiazhuang 050051, Hebei, PR China

Full list of author information is available at the end of the article
Hypercoagulability of blood, damage to the inner wall of blood vessels, and slowing of blood flow velocity are the physiological basis for the development of DVT [3]. These factors are often present in patients following a fracture. For example, the hypercoagulability of blood caused by the inflammatory reaction after fracture [4], and the slowing of blood flow caused by fixed restriction after fracture can promote the occurrence of lower limb DVT after a fracture [5]. Therefore, early prevention and diagnosis of preoperative thrombosis are particularly important for shortening the fracture healing time and restoring the bone and joint function. original author(s) and the source, provide a link to the Creative Commons licence, and indicate if changes were made. The images or other third party material in this article are included in the article's Creative Commons licence, unless indicated otherwise in a credit line to the material. If material is not included in the article's Creative Commons licence and your intended use is not permitted by statutory regulation or exceeds the permitted use, you will need to obtain permission directly from the copyright holder. To view a copy of this licence, visit http://creativecommons.org/licenses/by/4.0/. The Creative Commons Public Domain Dedication waiver (http://creativeco mmons.org/publicdomain/zero/1.0/) applies to the data made available in this article, unless otherwise stated in a credit line to the data. 
Based on thromboprophylaxis intervention, the incidence of lower extremity DVT in patients with fractures around the knee has been reported to be between $16.3 \%$ to $35 \%[6,7]$, of which $6.6 \%$ died of a pulmonary embolism [8]. Patients with fractures around the knee often require surgical treatment to restore knee function. Preoperative DVT seriously affects the timing of surgery and prolongs the treatment period. The patella is an essential structure during knee extension, and the incidence of patellar fractures ranges from $0.13 \%$ to $0.61 \%[9,10]$, accounting for $0.5 \%$ to $1.5 \%$ of the total incidence of fractures in adults $[11,12]$. At present, studies on fractures around the knee are mostly designed for femur, tibia, or knee fractures. To this date, only two studies have studied the relationship between patellar fractures and DVT; they found that the incidence of perioperative DVT in patellar fractures was $0.3 \%$ to $9 \%[2,13]$. However, these studies did not differentiate between preoperative and postoperative the incidence of DVT. In addition, reports on risk factors for DVT were inconsistent across studies. For example, Zhang et al. [2] found that preoperative time and plasma d-dimer were independent risk factors for DVT. While Li et al. [13] found that age $>50$ years, joint replacement, and operation duration exceeding $3 \mathrm{~h}$ were independent risk factors. However, only risk factors for DVT in patients with fractures of the entire lower limb were considered in these studies. Moreover, their studies have been inconsistent regarding risk factors for DVT after patellar fracture.

The purpose of our study is to retrospectively analyze the incidence, location, and risk factors of preoperative bilateral lower extremity DVT diagnosed by DUS of patients with isolated patella fracture admitted to our hospital.

\section{Materials and methods Patients}

This study retrospectively collected information on patients with patellar fracture treated in our hospital from January 2013 to December 2019. This study was approved by the Ethics Committee of the Third Hospital of Hebei Medical University. The inclusion criteria were age $>18$ years with an isolated patellar fracture requiring surgical treatment. The exclusion criteria were bilateral patellar fractures, multiple fractures, open fractures, old fractures and pathological fractures, use of blood circulation pumps, autoimmune diseases, anticoagulant use within 3 months of admission, and incomplete medical records.

After admission, all patients received routine basic prophylaxis (e.g. lower limb elevation and deep breath) and chemoprophylaxis (subcutaneous injection of low molecular weight heparin, 2500-4100 IU, once daily).
All patients routinely received Intermittent Pneumatic Compression Devices(IPCD)to prevent thrombosis [14, 15]. For patients allergic to LMWH, oral rivaroxaban was administered at a dosage of $10 \mathrm{mg}$ once daily. Owing to the simplicity of these prophylactic measures, patients had good compliance overall.

As per our policy, all patients were not allowed to perform any weight-bearing exercises during the preoperative period and were only allowed to perform ankle pump exercises and hook-toe exercises on the bed [16]. As from the first postoperative day, patients were encouraged to do equal-length exercise and straight leg tension exercises; and depending on the tolerance, non- or partialweight-bearing mobilization with the help of crutches was performed. At 6-8 weeks, the brace was removed after radiograph findings show no evidence of bone union. Resistance exercise was started, and complete weight-bearing mobilization was allowed.

\section{Data collection}

The data covered demographics, chronic comorbidities, and laboratory biomarkers. These include age, gender, body mass index (BMI), smoking, hypertension, diabetes, cerebrovascular disease, chronic heart disease, lung disease, any surgery history, time from injury to Doppler Ultrasound (DUS) examination, the American Society of Anesthesiologist (ASA) score; Laboratory tests included measurements of levels of total protein (TP), albumin (ALB), alanine transaminase (ALT), aspartate aminotransferase (AST), alkaline phosphatase (ALP), high-sensitivity C-reactive protein (HCRP), creatine kinase $(\mathrm{CK})$, lactic dehydrogenases (LDH), total cholesterol (TC), triglycerides (TG), glucose (GLU), D-dimer, fibrinogen (FIB), fibrinogen degradation product (FDP), and routine blood examinations included: white blood cells (WBC), neutrophils (NEU), lymphocytes (LYM), red blood cell (RBC), hemoglobin (HGB) level, hematocrit (HCT), platelets (PLT), prothrombin time (PT), prothrombin activity (PTA), international normalized ratio (INR), activated partial thromboplastin time (APTT), and thrombin time (TT).

\section{Diagnosis criteria of thrombosis}

After admission and before surgery, the patients were tested for DUS every 3 days, and if the surgery date was less than 3 days, DUS was performed a day before surgery. The "Guidelines for the Diagnosis and Treatment of Deep Vein Thrombosis (2016 3rd Edition)" issued by the Chinese Medical Association was used to diagnose and treat DVTs. Positive diagnostic criteria for DVT included (a) loss or incompressibility of the vein, (b) lumen obstruction or filling defects, (c) lack of respiratory variability in the vein segments above the knee, and 
(d) insufficient increase in blood flow during compression of the leg and foot. The common femoral vein, femoral vein, deep femoral vein, popliteal vein, posterior tibial vein, anterior tibial vein, and peroneal vein were assessed.

According to the thrombotic test criteria, the medical sonographer examined and reported the findings of the femoral vein trunk and the femoral deep, superficial, popliteal, tibial, and peroneal veins of both lower extremities. For patients with deep vein thrombosis, we only perform temporary fracture fixation after the thrombosis is first found, and then transfer the fracture to vascular surgery for diagnosis and treatment by professional vascular surgeons. After the condition is stable, orthopedic and vascular surgeons will evaluate the timing of surgery. Proximal DVT was defined as thrombi in the popliteal vein and above. The DVTs below the popliteal vein were considered as distal DVT. The clinical significance of thrombi in the intermuscular vein, small saphenous vein, and the great saphenous vein was relatively small; therefore, they were excluded from this study [17].

\section{Statistical analysis}

SPSS 25.0 software (IBM, Armonk, New York, USA) was used for statistical analysis. The measurement data were first explored using the Shapiro-Wilk test for their distribution status (normal or non-normal). Normal distribution data were expressed as mean \pm standard deviation (Sd), and an independent sample t-test was used to compare the differences between groups. The Mann-Whitney $\mathrm{U}$ test was used for non-normally distributed data. Categorical variables were assessed using the chi-square or Fisher's exact tests. $P$ values $<0.10$ in the univariate analyses were further analyzed by multivariate logistic regression. $P$ values $<0.05$ were considered statistically significant for all analyses.

\section{Results}

A total of 1,049 patients with patellar fractures were admitted during the study period. Among them, 73 patients were excluded because they were younger than 18 years; 39 due to bilateral patellar fracture and nonsurgical treatment; 41 due to multiple fractures, open fractures, old fractures, and pathological fractures; 16 due to use of blood circulation pumps, 25 due to autoimmune diseases, and use of anticoagulant drugs during the past 3 months and 28 due to incomplete medical records (Fig. 1).

A total of 827 patients with patellar fractures were included in this study. Of these, $63.0 \%$ (521/827) were males, and 37\% (306/827) were females, with an average age of 51.9 years ( $\mathrm{Sd}, 14.9$; range, $18-92$ years), and $20.1 \%(166 / 827)$ were aged 65 years or above. The average BMI was 24.6 ( $\mathrm{Sd}$, 3.4; range 17.3-46.7). The mean days from admission to operation in the non-DVT and DVT groups were $4.2 \pm 2.8$ days and $8.7 \pm 4.6$ days, respectively (Table 1).

Among the DVT patients, 5.8\% (48/827) were found to have preoperative DVT, with $79.2 \%(38 / 48)$ in males and $20.8 \%(10 / 48)$ in females. Their average age was 57.0 years ( $\mathrm{Sd}, 15.5$, range $28-90$ years). The average BMI was (24.2 \pm 3.02$)$; range (18.7-30.1). In addition, $25 \%$ $(12 / 48)$ of patients were 65 years or older. From injury to DVT diagnosis, the average time was (7.6 \pm 4.5$)$; range (1-24 days). All DVTs were asymptomatic.

Among the DVT patients, 22 had left-sided fractures, and 26 had right-sided fractures. Of the 22 patients with left-sided fracture, 21 had thrombus in the injured extremity, and 1 had thrombus in the bilateral extremity. Among the 26 patients with right-sided fractures, the thrombus was found in the injured extremity, uninjured extremity, and bilateral extremity in 20, 4, and 2 patients, respectively (Table 2). Among the patients with DVT, there were 9 (18.8\%) proximal DVT and 39 (81.2\%) distal DVT, respectively (Table 3). The distribution of thrombus in blood vessels was as follows: 1 in the femoral superficial vein, 7 in the popliteal veins, 20 in the peroneal veins, and 20 in the posterior tibial veins in patients with leftsided fractures; and 1 in the femoral superficial vein, 2 in the popliteal veins, 15 in the peroneal veins, and 9 in the posterior tibial veins in patients with right-sided fractures. None of the patients developed preoperative pulmonary embolism.

Comparison of the variables between the DVT and non-DVT groups showed statistically significant differences in sex, age, time from injury to DUS, ALB lower limit, ALT upper limit, NEUT upper limit, and D-dimer upper limit $(P<0.05$, Table 1$)$.

In the multivariate logistic regression model analysis, age (each increase 1 year), $(\mathrm{OR}=1.02)$, delay from injury to DUS (in each day, $\mathrm{OR}=1.33$ ), and elevated plasma D-dimer level $(>0.5 \mu \mathrm{g} / \mathrm{mL}, \mathrm{OR}=2.47)$ were identified as independent risk factors for preoperative DVT (Table 4).

\section{Discussion}

DVT is a common complication in patients with fractures, potentially affecting their prognosis. However, there are many uncertainties about the risk factors associated with thrombus formation. It is therefore essential to understand the significance of preoperative DVT in patients with isolated patellar fractures. In this study, we found that the preoperative incidence of DVT after patellar fracture was $5.8 \%(48 / 827)$, and $85.4 \%(41 / 48)$ of those occurred in the injured extremity. We also found that the associated risk factors were age, time from injury to DUS, and plasma D-dimer level. DVT is a common problem in patients with fractures and has been widely discussed in 


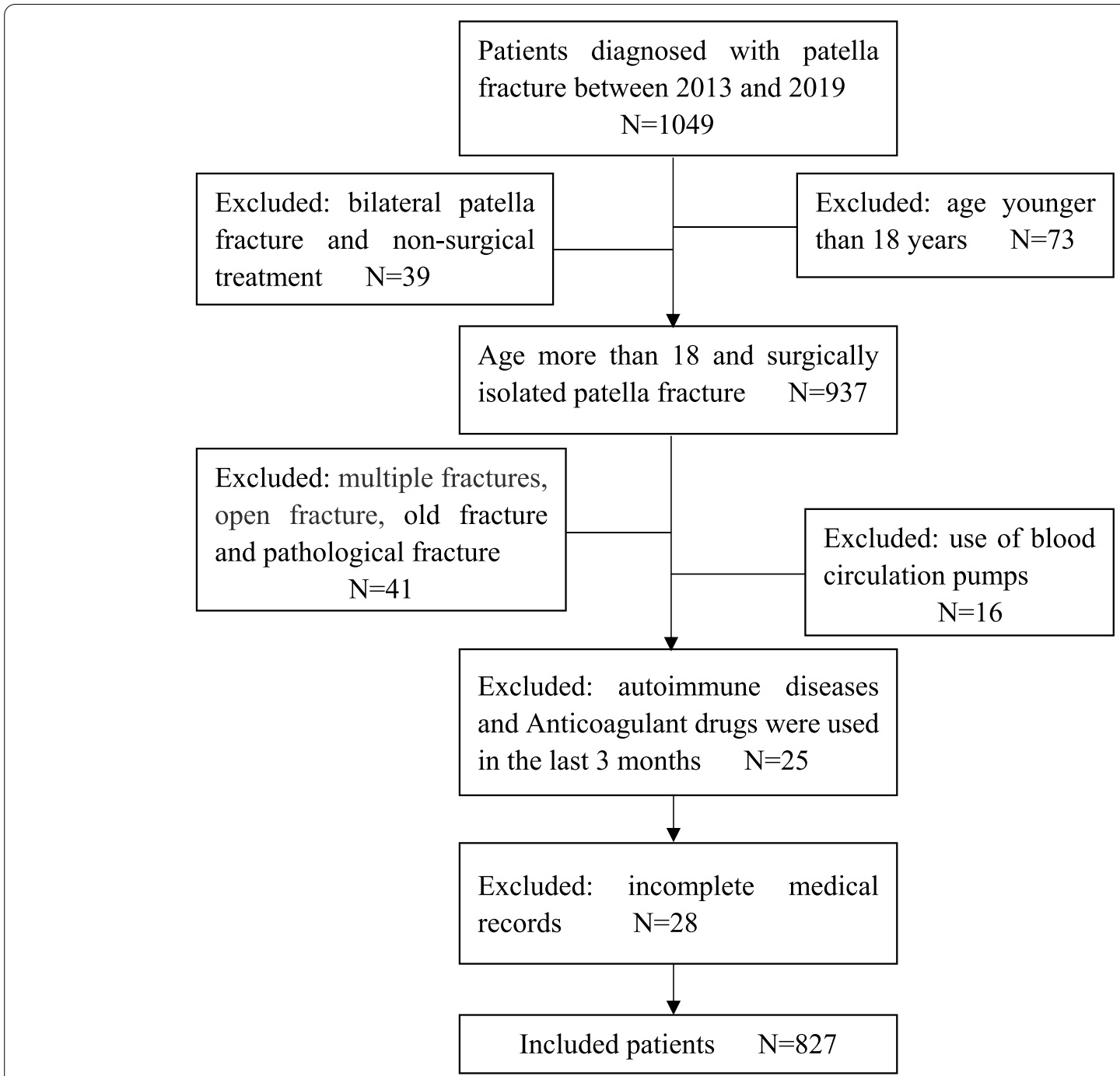

Fig. 1 Flow chart of patient inclusion and exclusion in this study

clinical practice [18]. We found a 5.8\% (48/827) preoperative incidence of DVT after an isolated patellar fracture. However, Wang et al. [19] reported an incidence of DVT in $15.3 \%$ of 59 patellar fractures. Li et al. [13] also reported an overall $8.2 \%$ rate in lower extremity fractures, with $9 \%$ of DVT in 177 knee fractures. The use of DUS, compared to the use of computed tomography (CT) or magnetic resonance imaging (MRI) venography for the detection of DVTs, may partly explain the relatively large gap in incidence rates. We also found that DVTs occurred not only in the injured extremity but also in the non-injured extremity, which is consistent with the findings of Wang et al. [20] This is due to the hypercoagulable state of blood after fracture and the patient's long-term lack of exercise in bed, which leads to not only the affected limb prone to thrombosis, but also the healthy limb prone to thrombosis. This suggests the equal importance of screening for DVT in both the noninjured and injured extremities.

Among patients with a patellar fracture in this study, the risk of DVT in men was 2.25 times that of women, and the average age was 56.9 years, indicating that middle-aged and older men were risk factors for DVT following a patellar fracture. Similarly, men were also found to be a risk factor for perioperative DVT in two previous studies on tibial fractures and ankle fractures [21, 22]. Estrogen is a risk factor for blood clots in younger women, while lower hormone levels in older women reduced DVT risk in women [23]. In line with this view, scholars also found that postmenopausal women are less likely to develop DVT [24]. Therefore, estrogen levels in the body may be responsible for the discrepancies between gender and the risk of DVT development found in our study. 
Table 1 Univariate analyses of risk factors associated with preoperative DVT following Patellar fracture

\begin{tabular}{|c|c|c|c|}
\hline Variables & NO. (\%) without DVT $(n=779)$ & NO. (\%) with DVT $(n=48)$ & $P$ value \\
\hline Gender & & & 0.017 \\
\hline Man & $483(62.0)$ & $38(79.2)$ & \\
\hline Woman & $296(38.0)$ & $10(20.8)$ & \\
\hline Age (years) & $51.6 \pm 14.8$ & $56.9 \pm 15.4$ & 0.016 \\
\hline Smoking & $88(11.3)$ & $9(18.8)$ & 0.119 \\
\hline $\mathrm{BMI}, \mathrm{kg} / \mathrm{m}^{2}$ & $24.7 \pm 3.3$ & $24.2 \pm 3.0$ & 0.407 \\
\hline$<18$ & $182(23.3)$ & $17(37.4)$ & \\
\hline $18-23.9$ & $268(34.4)$ & $18(37.5)$ & \\
\hline $24.0-27.9$ & $256(32.9)$ & $8(16.7)$ & \\
\hline$\geq 28$ & $73(9.4)$ & $5(10.4)$ & \\
\hline Hypertension & $175(22.5)$ & $11(22.9)$ & 0.942 \\
\hline Diabetes & $94(12.1)$ & $5(10.4)$ & 0.733 \\
\hline Cerebrovascular disease & $58(7.4)$ & $5(10.4)$ & 0.451 \\
\hline Chronic heart disease & $182(23.4)$ & $15(31.3)$ & 0.213 \\
\hline Lung disease & $5(0.6)$ & $1(2.1)$ & 0.253 \\
\hline Surgery history & $147(18.9)$ & $7(14.6)$ & 0.459 \\
\hline Mean days from admission to operation (days) & $4.2 \pm 2.8$ & $8.7 \pm 4.6$ & 0.001 \\
\hline Time from injury to DUS (days) & $3.1 \pm 2.7$ & $7.6 \pm 4.5$ & 0.001 \\
\hline Time from injury to anticoagulation (days) & $1.1 \pm 0.7$ & $1.3 \pm 0.5$ & 0.351 \\
\hline ASA & & & 0.488 \\
\hline$|-| \mid$ & $691(88.7)$ & $41(85.4)$ & \\
\hline III-IV & $88(11.3)$ & $7(14.6)$ & \\
\hline $\operatorname{TP}(<60 \mathrm{~g} / \mathrm{L})$ & $70(9.0)$ & $8(16.7)$ & 0.077 \\
\hline $\mathrm{ALB}(<35 \mathrm{~g} / \mathrm{L})$ & $59(7.6)$ & $9(18.8)$ & 0.006 \\
\hline ALT (> upper limit) & $61(7.8)$ & $8(16.7)$ & 0.032 \\
\hline AST (> upper limit) & $31(4.0)$ & $3(6.3)$ & 0.442 \\
\hline ALP (> upper limit) & $8(1.0)$ & $2(4.2)$ & 0.053 \\
\hline $\operatorname{HCRP}(>8 \mathrm{mg} / \mathrm{L})$ & $361(46.3)$ & $28(58.3)$ & 0.106 \\
\hline CK (> upper limit) & $63(8.1)$ & $5(10.4)$ & 0.569 \\
\hline $\mathrm{LDH}(>250 \mathrm{U} / \mathrm{L})$ & $61(7.8)$ & $7(14.6)$ & 0.098 \\
\hline $\mathrm{TC}(>5.8 \mathrm{mmol} / \mathrm{L})$ & $124(15.9)$ & $5(10.4)$ & 0.308 \\
\hline $\mathrm{TG}(>1.7 \mathrm{mmol} / \mathrm{L})$ & $150(19.3)$ & $9(18.8)$ & 0.931 \\
\hline $\mathrm{GLU}(>6.1 \mathrm{mmol} / \mathrm{L})$ & $255(32.7)$ & $18(37.5)$ & 0.496 \\
\hline $\operatorname{WBC}\left(>10^{*} 10^{9} / \mathrm{L}\right)$ & $182(23.4)$ & $17(35.4)$ & 0.058 \\
\hline NEUT $\left(>6.3^{*} 10^{9} / \mathrm{L}\right)$ & $314(40.3)$ & $27(56.3)$ & 0.029 \\
\hline $\operatorname{LYMT}\left(<1.8^{*} 10^{9} / \mathrm{L}\right)$ & $167(21.4)$ & $13(27.1)$ & 0.358 \\
\hline RBC (<lower limit) & $195(25.0)$ & $14(29.2)$ & 0.522 \\
\hline HGB (<lower limit) & $142(18.2)$ & $11(22.9)$ & 0.417 \\
\hline HCT (<lower limit) & $341(43.8)$ & $23(47.9)$ & 0.575 \\
\hline $\operatorname{PLT}\left(>300^{*} 10^{9} / \mathrm{L}\right)$ & $24(3.1)$ & $4(8.3)$ & 0.051 \\
\hline PT (> $12.5 \mathrm{~s})$ & $9(14.0)$ & $1(14.6)$ & 0.568 \\
\hline PTA $(<80 \%)$ & $46(5.9)$ & $3(6.3)$ & 0.922 \\
\hline INR $(>1.4)$ & $25(3.2)$ & $1(2.1)$ & 0.664 \\
\hline $\operatorname{APTT}(<28 s)$ & $219(28.1)$ & $18(37.5)$ & 0.163 \\
\hline $\mathrm{TT}(>17 \mathrm{~s})$ & $81(10.4)$ & $3(6.3)$ & 0.356 \\
\hline $\mathrm{FIB}(>4 \mathrm{~g} / \mathrm{L})$ & $118(15.1)$ & $11(22.9)$ & 0.150 \\
\hline $\mathrm{FDP}(>5 \mathrm{mg} / \mathrm{L})$ & $129(16.6)$ & $13(27.1)$ & 0.061 \\
\hline D-dimer (>0.5 ug/mL) & $205(26.3)$ & $33(68.8)$ & 0.001 \\
\hline
\end{tabular}

Notes: ALT Alanine transaminase, reference range: female, 7-40 U/L; male, 9-50 U/L; AST Aspartate transaminase, reference range: female, 13-35 U/L; male, 15-40 U/L; ALP Alkaline phosphatase, reference range: female, 35-100 U/L; male, 45-125 U/L; CK Creatine kinase, reference range: female, 40-200 U/L; male, 50-310 U/L; CREA creatinine, reference range: female, 41-73 umol/L; male, 57-111 umol/L; UA Uric acid; reference range: female, 155-357 umol/L; male, 208-248 umol/L; RBC Red

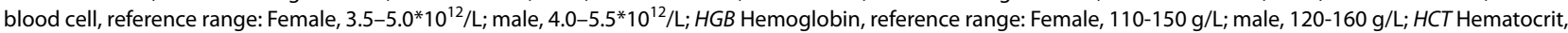
reference range: Female, $35-45 \%$; male, $40-50 \%$ 
Table 2 Distribution of thrombus in lower extremities

\begin{tabular}{lllll}
\hline Fracture sides & \multicolumn{2}{l}{ Thrombus } & & \\
\cline { 2 - 5 } & Injured extremity & $\begin{array}{l}\text { Uninjured } \\
\text { extremity }\end{array}$ & Bilateral & Total \\
\hline Left fracture & $21(95.4)$ & $0(0.0)$ & $1(4.6)$ & $22(100)$ \\
Right fracture & $20(76.9)$ & $4(15.4)$ & $2(7.7)$ & $26(100)$ \\
Total & $41(85.4)$ & $4(8.3)$ & $3(6.3)$ & $48(100)$ \\
\hline
\end{tabular}

Table 3 The distribution of thrombus in blood vessels

\begin{tabular}{llll}
\hline Fracture sides & Proximal DVT & Distal DVT & Total \\
\hline Left fracture & $2(9.1)$ & $20(90.9)$ & $22(100)$ \\
Right fracture & $7(26.9)$ & $19(73.1)$ & $26(100)$ \\
Total & $9(18.8)$ & $39(81.2)$ & $48(100)$ \\
\hline
\end{tabular}

Table 4 Multivariate analyses of risk factors associated with preoperative DVT after patellar fracture

\begin{tabular}{lll}
\hline Variable & OR and 95\%Cl & P value \\
\hline Gender (male us female) & $2.25(1.04-4.90)$ & 0.040 \\
$\begin{array}{l}\text { Time from injury to DUS (in each } \\
\text { day delay) }\end{array}$ & $1.29(1.20-1.39)$ & 0.001 \\
\begin{tabular}{l} 
D-dimer level $(>0.5 \mathrm{ug} / \mathrm{ml})$ \\
\hline
\end{tabular} & $2.28(1.61-3.22)$ & 0.001 \\
\hline
\end{tabular}

Our results showed that the preoperative duration was significantly longer in the DVT group than in the non-DVT group, with a $33 \%$ increased risk of preoperative DVT for each day of delay from the injury to DUS. Consistently, Zuo et al. [25] found that the duration before admission to the hospital in the DVT group was longer than in the non-DVT group after intertrochanteric fractures, and the risk of DVT was increased by $37 \%$ each day of delay to admission. The hypercoagulable state after trauma is the pathophysiological basis of DVT. In particular, the blood coagulation dynamic value was the highest in the first $24 \mathrm{~h}$ after the trauma and remained hypercoagulable during the first 4 days [26]. Similar conclusions were reached in the study conducted by Decker et al. [27] Therefore, we recommend routine DVT screening for all fracture patients after admission and surgery within 24-48 h after injury, which should provide the feasibility of reducing perioperative adverse events [28]. In addition, more attention should be paid to patients with delayed admission of more than 3 days to avoid missed diagnosis of DVT. Fractures are often accompanied by crush injuries, which can cause bleeding to compress veins, resulting in hemodynamic disruption, as well as damage to the veins themselves, particularly the endothelial cells. These can lead to blood clots. We suggest that patients with patellar fracture on preoperative double lower limbs DUS, especially after the injury, the official guidelines suggest don't regular scans, but the results of this study showed that the preoperative blood clots in the patellar fracture patients have a higher risk, so for fracture patients, not just the patellar fracture patients, should be thoroughly DVT after hospital screening, and surgery as soon as possible.

Reports have shown that D-dimer is a highly sensitive laboratory marker for DVT $[29,30]$. Our results showed that $\mathrm{D}$-dimer levels above $0.5 \mathrm{ug} / \mathrm{ml}$ at admission were associated with a $47 \%$ increased risk of DVT, which was comparable to the findings of Zhang et al's study of lower extremity fractures [2]. D-dimer is a fibrin degradation marker that represents secondary fibrinolytic activity in the blood, which has clinical value in the diagnosis of thrombotic events [31, 32]. Yamasaki et al. [33] retrospectively collected 588 patients undergoing lumbar spine surgery and found that the risk of DVT increased by $9 \%$ with $\mathrm{D}$-dimer level greater than $19.2 \mathrm{ug} / \mathrm{ml}$ one week after surgery. However, the cut-off values used in various research were highly variable, which may be due to the heterogeneity of the subjects and the study designs. Therefore, the age-adjusted D-dimer levels could be a better predictive model clinically. It is important to note that the incidence of preoperative thrombosis was $5.8 \%(48 / 827)$ in all of our patients with patellar fractures, despite thrombosis prophylaxis, thus indirectly highlighting the importance of breakthrough thrombosis.

Our study presents several limitations. Firstly, since it was a retrospective study, some information might have been missed during data collection. We did not capture the data regarding the past history of thrombosis or family history, which is a limitation of this study. Secondly, we might have under-report DVTs since we used DUS, which has a relatively lower sensitivity compared to CT or MRI angiography. Considering that angiography is an invasive examination, routine DUS for DVT screening is acceptable and is generally used in most medical centers. Thirdly, patients in both groups did not perform off-bed weightbearing exercises preoperatively because of pain related to the fracture, which may affect the occurrence of DVT. Therefore, the causative relationship of variables with DVT could not be established. Instead, there is a combination that should be cautiously during interpretation.

\section{Conclusions}

In summary, when patients were not allowed to get out of bed and exercise before surgery, the incidence of preoperative DVT following an isolated patellar fracture was $5.8 \%$. 
Age (each increase 1 year), delay from injury to DUS, and elevated plasma D-dimer levels were independent risk factors for preoperative thrombosis. Despite a low prevalence of DVT after an isolated patellar fracture, this study underscores the importance of identifying those at a high risk of developing DVT, especially those with multiple identifiable factors, and encourage the early targeted use of antithromboembolic agents to reduce DVT occurrence.

\section{Acknowledgements}

None

\section{Authors' contributions}

Wei Chen and Yanbin Zhu contributed to the conception or design of the work. Qun Wei and Kai Ding. contributed to the acquisition, analysis, and interpretation of data. Yuxuan Jia, Ming Li. and Chao Li contributed to the creation of new software used in the work. Weijie Yang and Haicheng Wang contributed to the drafting of the work and substantial revision of it. All authors reviewed the manuscript. All authors have approved the submitted version.

\section{Funding}

This study was supported by the National Natural Science Foundation of China (Grant number 82072447), High-level Talent Project in Hebei Province (Grant number A201903007).

\section{Availability of data and materials}

The datasets generated and/or analysed during the current study are not publicly available due to limitations of ethical approval involving the patient data and anonymity but are available from the corresponding author on reasonable request.

\section{Declarations}

\section{Ethics approval and consent to participate}

This study was approved by the ethics committee of the 3rd Hospital of Hebei Medical University. All methods were carried out in accordance with the relevant guidelines and regulations, and all participants gave their informed consent. All participants were enrolled as adults. This study conforms to the provisions of the Declaration of Helsinki.

\section{Consent for publication}

Not Applicable.

\section{Competing interests}

The authors declare no competing interests. All authors have approved the submitted version (and any substantially modified version that involves the author's contribution to the study).

\section{Author details}

${ }^{1}$ Trauma Emergency Center, Key Laboratory of Biomechanics of Hebei Province, the Third Hospital of Hebei Medical University, No. 139 Ziqiang Road, Qiaoxi District, Shijiazhuang 050051, Hebei, PR China. ${ }^{2}$ Department of Hospital Infection Control, Department of Public Health, Hebei General Hospital, Shijiazhuang 050051, Hebei, PR China. ${ }^{3}$ Department of Clinical Medicine, School of Basic Medicine, Hebei Medical University, Shijiazhuang, Hebei, PR China.

Received: 28 October 2021 Accepted: 28 February 2022

Published online: 03 March 2022

\section{References}

1. Wigner NA, Donegan DJ. Current concepts in deep vein thrombosis and pulmonary embolism after trauma. J Curr Orthop Pract. 2014;25(3):208-12.

2. Zhang W, Huai Y, Wang W, Xue K, Chen L, Chen C, Qian A. A Retrospective cohort study on the risk factors of deep vein thrombosis (DVT) for patients with traumatic fracture at Honghui Hospital. BMJ Open. 2019;9(3):e024247.
3. Wolberg AS, Rosendaal FR, Weitz Jl, Jaffer IH, Agnelli G, Baglin T, Mackman N. Venous thrombosis. J Nat Rev Dis Primers. 2015;1:15006.

4. Ma Y, Zhou Y, Wu F, Ji W, Zhang J, Wang X. The Bidirectional Interactions Between Inflammation and Coagulation in Fracture Hematoma. J Tissue Eng Part B Rev. 2019;25(1):46-54.

5. Testroote M, Stigter WA, Janssen L, Janzing HM. Low molecular weight heparin for prevention of venous thromboembolism in patients with lower-leg immobilization. J Cochrane Database Sys Rev. 2014(4):Cd006681.

6. Zhang J, Li J, Zhao K, Meng H, Zhu Y, Zhang Y, Chen W. Post-operative deep vein thrombosis in patients over sixty years of age diagnosed with closed distal femur fractures undergoing open reduction internal fixation. J Int Orthop. 2021:45(6):1615-23.

7. Zhu Y, Chen W, Li J, Zhao K, Zhang J, Meng H, Zhang Y, Zhang Q. Incidence and locations of preoperative deep venous thrombosis (DVT) of lower extremity following tibial plateau fractures: a prospective cohort study. J Orthop Surg Res. 2021;16(1):113.

8. Wahlsten LR, Eckardt H, Lyngbæk S, Jensen PF, Fosbøl EL, Torp-Pedersen C, Gislason GH, Olesen JB. Symptomatic venous thromboembolism following fractures distal to the knee: a nationwide Danish cohort study. J Bone Joint Surg Am. 2015;97(6):470-7.

9. Yang NP, Chan CL, Yu IL, Lee CY, Chou P. Estimated prevalence of orthopaedic fractures in Taiwan-A cross-sectional study based on nationwide insurance data. J Injury. 2010;41(12):1266-72.

10. Chen W, Lv H, Liu S, Liu B, Zhu Y, Chen X, Yang G, Liu L, Zhang T, Wang H, et al. National incidence of traumatic fractures in China: a retrospective survey of 512187 individuals. J Lancet Glob Health. 2017:5(8):e807-17.

11. Springorum HP, Siewe J, Dargel J, Schiffer G, Michael JW, Eysel P. Classification and treatment of patella fractures. J Der Orthopade. 2011;40(10):877-80, 882.

12. Sayum Filho J, Lenza M, Teixeira de Carvalho R, Pires OG, Cohen M, Belloti JC. Interventions for treating fractures of the patella in adults. J Cochrane Database Syst Rev. 2015(2):Cd009651.

13. Li Q, Chen X, Wang Y, Li L. Analysis of the occurrence of deep venous thrombosis in lower extremity fractures: a clinical study. Pak J Med Sci. 2018;34(4):828-32.

14. Niikura T, Lee SY, Oe K, Koh A, Koga T, Dogaki Y, Okumachi E, Kurosaka M. Venous thromboembolism in Japanese patients with fractures of the pelvis and/or lower extremities using physical prophylaxis alone. J Orthop Surg (Hong Kong). 2012;20(2):196-200.

15. Takahashi Y, Takahira N, Shibuya M, Uchiyama K, Fukushima K, Iwase D, Kawamura T, Miyagi M, Higashiyama R, Moriya M, et al. A portable pneumatic compression device to prevent venous thromboembolism in orthopedic patients with the highest risks of both venous thrombosis and bleeding: a case series study. J Orthop Surg (Hong Kong). 2020;28(1):2309499020905711.

16. Craik JD, Clark A, Hendry J, Sott AH, Hamilton PD. The effect of ankle joint immobilization on lower limb venous flow. J Foot Ankle Int. 2015;36(1):18-23.

17. Stavem K, Skjaker SA, Hoel H, Naumann MG, Sigurdsen U, Ghanima W, Utvåg SE. Risk factors for symptomatic venous thromboembolism following surgery for closed ankle fractures: a case-control study. J Foot Ankle Surg. 2020;26(6):681-6.

18. Zhang BF, Wei X, Huang H, Wang PF, Liu P, Qu SW, Li JH, Wang H, Cong YX, Zhuang $Y$, et al. Deep vein thrombosis in bilateral lower extremities after hip fracture: a retrospective study of 463 patients. J Clin Interv Aging. 2018;13:681-9.

19. Wang H, Kandemir U, Liu P, Zhang H, Wang PF, Zhang BF, Shang K, Fu YH, Ke C, Zhuang $Y$, et al. Perioperative incidence andlocations of deep vein thrombosis following specific isolated lower extremityfractures. J Injury. 2018;49(7):1353-7.

20. Wang PF, Li JH, Fei C, Li Z, Ke C, Shang K, Cong YX, Qu SW, Zhang BF, Zhuang Y, et al. Deep Vein Thrombosis in the Uninjured Limb in Patients with Lower Extremity Fractures: a retrospective study. J BioMed Res Int. 2020;2020:1647617.

21. Jupiter DC, Saenz F, Mileski W, Shibuya N. Acute Deep Venous Thrombosis and Pulmonary Embolism in Foot and Ankle Trauma in the National Trauma Data Bank: An Update and Reanalysis. J Foot Ankle Surg. 2019;58(6):1152-62.

22. Liu D, Zhu Y, Chen W, Li J, Zhao K, Zhang J, Meng H, Zhang Y. Relationship between the inflammation/immune indexes and deep venous 
thrombosis (DVT) incidence rate following tibial plateau fractures. J Orthop Surg Res. 2020;15(1):241.

23. Bleker SM, Coppens M, Middeldorp S. Sex, thrombosis and inherited thrombophilia. J Blood Rev. 2014;28(3):123-33.

24. Proctor MC, Wainess RM, Henke PK, Upchurch GR, Wakefield TW. Venous thromboembolism: regional differences in the nationwide inpatient sample, 1993 to 2000. J Vascular. 2004;12(6):374-80.

25. Zuo J, Hu Y. Admission deep venous thrombosis of lower extremity after intertrochanteric fracture in the elderly: a retrospective cohort study. J Orthop Surg Res. 2020;15(1):549.

26. Schreiber MA, Differding J, Thorborg P, Mayberry JC, Mullins RJ. Hypercoagulability is most prevalent early after injury and in female patients. $J$ Trauma. 2005;58(3):475-80 ; discussion 480-471.

27. Decker S, Weaver MJ. Deep venous thrombosis following different isolated lower extremity fractures: what is known about prevalences, locations, risk factors and prophylaxis? Eur J Trauma Emerg Surg. 2013;39(6):591-8.

28. Karres J, Kieviet N, Eerenberg JP, Vrouenraets BC. Predicting Early Mortality After Hip Fracture Surgery: The Hip Fracture Estimator of Mortality Amsterdam. J Orthop Trauma. 2018;32(1):27-33.

29. Bakhshi H, Alavi-Moghaddam M, Wu KC, Imami M, Banasiri M. D-dimer as an applicable test for detection of posttraumatic deep vein thrombosis in lower limb fracture. Am J Orthop (Belle Mead, NJ). 2012;41(6):E78-80.

30. Cuker A, Arepally GM, Chong BH, Cines DB, Greinacher A, Gruel Y, Linkins LA, Rodner SB, Selleng S, Warkentin TE, et al. American Society of Hematology 2018 guidelines for management of venous thromboembolism: heparin-induced thrombocytopenia. J Blood Adv. 2018;2(22):3360-92.

31. Reikeras $\mathrm{O}$, Clementsen $\mathrm{T}$. Thrombosis markers in hip versus knee arthroplasty: a pilot study. J Orthop Surg (Hong Kong). 2009;17(3):291-5.

32. Magetsari R, Dewo P, Nugroho AS, Lanodiyu Z. Deep Vein Thrombosis in Elderly Patients following Surgery for Fracture of the Proximal Femur. Malays Orthop J. 2014;8(3):7-10.

33. Yamasaki K, Hoshino M, Omori K, Igarashi H, Tsuruta T, Miyakata H, Nemoto Y, Matsuzaki H, Iriuchishima T. Prevalence and risk factors of deep vein thrombosis in patients undergoing lumbar spine surgery. J Orthop Sci. 2017;22(6):1021-5.

\section{Publisher's Note}

Springer Nature remains neutral with regard to jurisdictional claims in published maps and institutional affiliations.

Ready to submit your research? Choose BMC and benefit from:

- fast, convenient online submission

- thorough peer review by experienced researchers in your field

- rapid publication on acceptance

- support for research data, including large and complex data types

- gold Open Access which fosters wider collaboration and increased citations

- maximum visibility for your research: over 100M website views per year

At BMC, research is always in progress.

Learn more biomedcentral.com/submissions 